Int. J. Electrochem. Sci., 12 (2017) 2219 - 2231

\title{
Synthesis and Application of 2'-(5-Bromo-2- hydroxybenzylidene) Toluenesulfonohydrazide as a Shift Base Ionophore for Highly Selective Copper(II) Membrane Electrode
}

\author{
Illyas Md Isa ${ }^{1,2, *}$, Nazihah Mohd Noor ${ }^{1}$, Yusnita Juahir ${ }^{1}$, Norhayati Hashim ${ }^{1,2}$, Hapipah Mohd Ali ${ }^{3}$ \\ ${ }^{1}$ Department of Chemistry, Faculty of Science and Mathematics, Universiti Pendidikan Sultan Idris, \\ 35900 Tanjong Malim, Perak, Malaysia \\ ${ }^{2}$ Nanotechnology Research Centre, Faculty of Science and Mathematics, Universiti Pendidikan Sultan \\ Idris, 35900 Tanjong Malim, Perak, Malaysia \\ ${ }^{3}$ Department of Chemistry, Faculty of Science, University of Malaya, 50603 Kuala Lumpur, Malaysia \\ *Email: illyas@fsmt.upsi.edu.my
}

doi: $10.20964 / 2017.03 .28$

Received: 9 September 2016 / Accepted: 10 January 2017 / Published: 12 February 2017

The construction of a potentiometric copper(II) ion electrode based on 2'-(5-bromo-2hydroxybenzylidene) toluenesulfonohydrazide (5BrSALMeBSH) as an ionophore has been developed. The designed electrode having a different composition of poly(vinyl chloride) (PVC), plasticizers and ionophore showed that sensor with membrane composition 5BrSALMeBSH: PVC: DOP in the ratio of 7:40:56 (w/w) gave the best response. It exhibited a wide linear response with a Nernstian slope of $29.34 \mathrm{mV}$ per decade over the concentration range of $1.0 \times 10^{-5}-1.0 \times 10^{-1} \mathrm{M} \mathrm{Cu}$ (II) ions. Under the optimized conditions, the electrode has a detection limit of $3.98 \times 10^{-6} \mathrm{M}$ and the working $\mathrm{pH}$ range of 3.0 - 6.0 with response time less than the 20s. The proposed electrode is stable for about two months and exhibits good selectivity for $\mathrm{Cu}(\mathrm{II})$ ions over $\mathrm{Zn}^{2+}, \mathrm{Co}^{2+}, \mathrm{Ni}^{2+}, \mathrm{Pb}^{2+}, \mathrm{Mg}^{2+}, \mathrm{Ba}^{2+}, \mathrm{Ca}^{2+}, \mathrm{Cd}^{2+}$, $\mathrm{Ce}^{3+}, \mathrm{K}^{+}, \mathrm{Na}^{+}$. Designation of this easy and inexpensive electrode was used to determine a copper ion in wastewater samples, and the results obtained shown a sync relation with spectroscopy method which is AAS method conducted.

Keywords: Copper(II) selective electrode, 2'-(5-bromo-2-hydroxybenzylidene)

toluenesulfonohydrazide, potentiometry, polymeric membrane electrode

\section{FULL TEXT}

(C) 2017 The Authors. Published by ESG (www.electrochemsci.org). This article is an open access article distributed under the terms and conditions of the Creative Commons Attribution license (http://creativecommons.org/licenses/by/4.0/). 